\title{
The Importance of Consultancy Project and How Can It Will Be Adopted in Kurdistan Universities as an Alternative to Replace the Summer Training (2016)/ Sulaimani Polytechnic University \& Cihan University/ Sulaimaniya
}

\author{
Chnar Abdullah Rashid ${ }^{1,2} * \quad$ Tazhan Muhammad Noori ${ }^{1,2}$ \\ 1-Technical college of Administration, Sulaimani Polytechnic University \\ 2- Faculty of Administration and Financial Science, Cihan University/ Sulaimaniya
}

\begin{abstract}
This research mainly focused on providing an alternative option to the summer training. The hypothesis has been made on the students who are not approved of the summer training and they hope to change it. For this purpose, we have created a questionnaire to achieve primary data and we gave it to the students at level 4 of university in Sulaimani Polytechnic University, in order to identify their happiness with this module. In the questionnaire, we have suggested that consultancy project can be adopted to alter the summer training. After receiving the responses, we have found that the majority of students considered that: the summer training can be changed into a better project and this somehow matched with the hypothesis given.
\end{abstract}

Keywords: summer training, alternative, internal \& external consultancy.

\section{Introduction}

Ever Since that Kurdistan Region Government has faced financial crisis, all the basic parties are in a wonder to discover a way in which they can pass this crisis. From this point of view, Ministry of Higher education has had attempted a lot of efforts to make some decisions regarding increasing revenues and decreasing expenditure. For this reason, we have decided to bring some foreign ideas for Kurdistan from UK's Universities because; their universities are working on a basis of earning money instead of spending money for universities. It is time for us to decide making Universities to be a source of finance.

The idea is studying marketing module by consultancy project as an alternative to summer training. For this purpose, we made a questionnaire to take the students' feedback who has participated summer training in order to know whether they are approve with summer training or not. If they do not, then, what is the reason behind it? And what kind of project can be altered? We hand out the questionnaire by paper to students at level 4 of accounting and finance department at the collage of administration in Sulaimani Polytechnic University. Because, they are the only students who has participated summer training in this department.

The purpose of this research is to identify whether our students are happy with summer training or not. Furthermore, to encourage government to make universities to be a source of finance.

\section{Literature review \\ 1-Consultancy's overview \\ Some introductions}

The person who is in a place in which helshe has some influence over a human being, a group, or an establishment is called consultant, but helshe has no immediate power to make changes or establish programs. A manager is someone who has direct responsibility over the work. The moment you are in charge, you are acting as a manager.

Anyone who is in a staff or support roles in firms are really consultants, even if they don't formal call themselves consultants. Support staff takes action in any establishment by planning, recommending, assisting, or advising in such matters as these: (Human resources or personnel, Financial analysis, Auditing, Systems analysis, Market research, Product design, Long-range planning, Organizational effectiveness, Safety, Training and development, And many more). (Block, 2011).

The receivers of all this recommendation are called client. Sometimes the client is a single individual. Other times, the client may be a team work, a department, or a whole establishment. The client is the person or persons whom the consultant wants to influence.

Line bosses are support people who provide services for the clients in an establishment, they have to work under the advice of support groups, whether it is in their interest or not. But by definition, any support work has no direct power over anything but its own time, its own internal staff, and the nature of the service it provides.

Your target or final product in any consulting activity is some kind of change. Change comes in two kinds. At one level, we consult to establish change in the line firm of a structural, policy, or procedural nature. For instance, a new compensation package, a new reporting process, or a new safety program. The second type 
of change: is the final out coming that one person or many people in the line firm have learned something up-todate. They may have been reached how to conduct better work measurements.

Consultation mostly used to describe any work you take with a regime of which you are not participant. Meeting someone who is a help seeker for an interview is a consulting performance. A survey of issues, a training program, estimation, a study all are consultations for the sake of change. The consultant's goal is to be part of in all the successful works that its outcome will be in people or firms managing themselves variously.

Every time you give suggestions to someone who is in a place to decide, you are consulting. For each of these moments of consultation, there are three types of skills you need to do a fine work: technical, interpersonal, and consulting skills. (Block, 2011).

\section{1-technical skills}

First of all, we need to know what the person is mentioning. We need people with skills about the question. Either in university or in our first career, we were trained in a specialized field or work. This might be engineering, sales, accounting, counseling, or any of the thousands of other ways people work. This is our main training. Then, after asking for some technical expertise, that we start consulting. If we didn't have some expertise, then people wouldn't demand for our suggestion.

\section{2- Interpersonal skills}

To work with people, we require having some interpersonal skills, that is, some ability to change thinking into work, to listen, to encourage, to not agreeing rationally, and to mainly maintain a relationship. These skills can be found in any books and seminars when people demanding help in this area. Actually, there is a whole industry about making better relationships that is directed to improving these skills. Just like technical skills, Interpersonal skills are important to influence consultation.

\section{3- Consulting skills}

Each consulting project, whether it finishes in ten minutes or ten months, undergoes five stages. The phases in each stage are in sequence, if you ignore one or think that it is done, you encounter issues. Skillful consulting is being competent in the execution of each of these phases.

\section{Consulting skills preview}

Here is an overlook of what is participated in the five stages of consulting.

Phase 1: entry and contracting

This stage has to do with the first contact with a client about the project. It contains setting up the initial meeting as well as brainstorming the issue, whether the consultant is the right individual to work on this problem, what the client's hopes are, what the consultant's expectations are, and how to begin. When consultants mention their problems, their finalization is usually that the project was full of flaws in the beginning contracting phase.

\section{Phase 2: discovery and dialogue}

Consultants are required to come up with their own sense of both the problem and the strengths the client has. This may be the most important thing they function. They also need skill in helping the client do the same. The questions here for the consultant are: who is going to be participated in defining the issue or circumstance? What ways will be used? What type of information should be gained? What time does it take? Should the inquiry be done by the consultant, or should it be done by the client?

\section{Phase 3: analysis and the decision to function}

The organization and the report about the inquiry and the dialogue must be in style. The consultant is usually in the place of minimizing large amounts of information to a solvable number of problems. There are also options for the consultant to make on how to make the client participate in the process of analyzing the data. In giving feedback to an establishment, there is always some opposition to the information (if it copes with necessary problems). The consultant must deal with this opposition before a suitable decision can be made about how to work. This stage is really what many people call planning. It includes setting ultimate targets for the project and choosing the best function steps or changes.

\section{Phase 4: involvement and implementation}

This includes managing the planning of stage 3. In most cases, the implementation may depend totally on the line firm. For major change trying, the consultant may be participated deeply. Some projects initiate with implementation with an educational happening. This could be a series of meetings to define some change, a single meeting to receive various parts of the establishment together to point to the issue, or a training phase. In these situations, the consultant is usually participated in rather complicated style work and in managing the meeting or training phase.

\section{Phase 5: extension, recycle, or finalization}

Phase 5 is about learning from involvement. It starts with the decision whether to maintain the process to a bigger fraction of the establishment. Sometimes it is not until after some implementation appears that an obvious figure of the actual issue penetrates. In this situation, the process recycles and a new contract needs to be studied. 
If the implementation was either a large success or a moderate-to-high failure, termination of further engagement on this project may be in the offing. There are many selections for terminating the relationship, and finalization should be considered a legitimate and necessary part of the consultation. If done properly, it can offer an important learning experience for the client and the consultant as well as opening new doors for communications. (Block, 2011).

\section{2- The consultant's targets}

Our estimations about what participation to effective consultant and manager work lead to a set of selective targets for each consulting job. Achieving each of these targets may not always be possible, but we can always be obvious about our selection.

\section{Goal: 1 builds a collaborative relationship}

There are two reasons for consultants to look for in collaborative relationships with their clients. One is that a sharing relationship promises maximum advantages of people's resources both the consultant's and the clients. It also spreads the responsibility for success or failure and for implementation, and it's a good way to work too. The second reason is that whether they know it or not, consultants are always working as models of how to tackle a problem. The motto contained in the method the consultants work is much more impressive than their sayings. To mention collaboration and act verily is confusing and self-defeating.

\section{Goal 2: tackle issues so they stay solved}

It is possible to function in such a way that only the sudden issue gets tackled. If the issue is that employees usually come late to work, for example, works can be taken to stop it: station the manager at the door in the morning with a pencil and a black book, or have room checks beginning time each morning, or issue a policy statement about being late. These functions might minimize the issue of lateness. And if internal or external consultants have been engaged in making these types of advices, they might have participated to an increase in the effectiveness of the establishment. But this does not mean that the managers have learned anything about how to tackle similar issues and thus become more rival.

\section{Goal 3: make sure focus is given to both the technical business issue and the relationships}

Each circumstance has two tools: the technical / business issue that has to be resolved and the method in which people are engaging around that issue. In most firms, basic focus is given to the technical / business problem. Consultants, however, are in a special location to define the people or process that resulted productively. As third group, they have no implemented intention in the process issues no force to achieve or lose, no territory to expand or contract, no budget to increase or decrease. Consultants can excrete attention to the process issues, and line bosses will listen to them more attentively than they listen to other. (Block, 2011).

\section{3- Summer training}

Summer training is one of the obligated module for each students in Kurdistan's Universities. This module have adopted from the beginning of the study in Kurdistan's Universities in some departments such as: (collage of Medical, sciences, human sciences). Every student has to participate in this module by going to another governmental organization or a private company but the majority of the students are choosing governmental organization. Students have rights to select which organization they want to participate. However, during 4 years of bachelor degree study there is only one module about governmental organizations' work which is Governmental Accounting module. If any students have not participated summer training she/he will fail in this module and she/he has to participate after on. There is no mark for this module only 2 years marks have been placed for the students. Every year the instructions about this module will be changed. The reason might be that this module is really important and necessary for students' knowledge but the way in which the students can achieve advantages from it is not appropriate.

The ministry of higher education and scientific research are spending money for this module. Whereas, this kind of module in the developed countries is a source of finance in the Universities. We attempted a lot to illustrate the budget which has been spent for this module in the last 10 years but unfortunately we could not.

\section{2- Methodology}

The research makes an attempt in discovering whether there is a way to provide an alternative project to summer training in the accounting and finance department in the administrative college of technics at Sulaimani Polytechnic University or not. It would be logical enough for the research methodology to analyze data and this could offer important insights into the scope of this research.

\section{2-1 Questionnaire}

The questionnaire was given to a 96 students at stage 4 in the accounting and finance department, because they are the only group in the mentioned department which have participated the summer training. The questionnaire consisted of 10 questions. 73 responses have been received out of 96 which mean nearly $76 \%$ and this number is good to analyze the questionnaire and to be reliable.

\section{2-2 Research Method}

This research is using quantitative method which is a research method that much more focused on the collection and analysis of numerical data and statistics but relies less on a small questionnaire, interviews, observations, 
focus groups, subjective reports and case studies (Waters, 2008),

\section{2-3 Data Collection}

Data is one of the most significant aspects of any research studies. Researches are conducting in different fields of study and they will be different in methodology but every research is based on data which is examined and interpreted to achieve information. The sources of data can be broadly classified into primary and secondary data. When data observed or collected directly from first-hand experience is called primary data and these data which is collected or published in the past is the secondary data. Primary data will be used for this research through questionnaire. The data collection instrument was a questionnaire which had ten questions and it sent to 96 students studying in accounting and finance department and we will use Microsoft excel to analyze the data which will be collected through the questionnaire. Through using primary data the reliability and validity of the research can be improved, for instance the results of questionnaire can be highly reliable. These data has not been published yet and it is more objective, also it has not been changed by human beings. Thus, it's validity is greater than secondary data. A research based only on secondary data is less reliable and might have biases because secondary data could have been already manipulated by human beings.

\section{2-4 Research Problems}

Ministry of higher education and scientific research is one of the Kurdistan Region Government's organizations that are struggling with financial crisis which has recently faced the government, in a way in which this ministry might decide to stop summer training because it costs the ministry and they do not have enough budgets to induct this duty. Consequently, the students will face problems, because they cannot practice what they learned during their academic years. While, practicing their studies is one of the obligations' requirements to achieve a bachelor degree.

\section{2-5 Research Importance}

Recently, Kurdistan Region Government Has faced financial crisis, because of decreasing oil prices, not sending Kurdistan's share of the Iraq's budget by central government, and fighting ISLS. Therefore, it is significant to work on it and to find a way to reduce expenditures and increase revenues. Hence, to discover a suitable way to provide revenue without depending on natural resources because, recently the countries that depending on it have achieved a huge deficiency in their budget because of the decline of the oil prices. The cause is decreasing demand and increasing supply is a basic reason to decline oil prices because of the decreasing economical growths of china and India which makes oil supply to be increased by 2000,000 bermil. For this reason, it is necessary to remove summer training and put an alternative for it. In spite the fact that these expenditures that have already existed now for summer training is not too much but, for a circumstance such this, it is vital to decrease expenditures, because it will be finally burden on the budget. Hence, stopping summer training is not enough to solve this problem. Whereas, it needs to alter a project in which it is not holding expenditures and it is increasing revenues as well. Therefore, the importance of this research is that, it is working on decreasing expenditures and increasing revenues without depending on natural resources. In the same time students can have opportunity to practice what they have studied and find a job in their near future. Subsequently, Universities can be a source of revenues in future.

\section{3- Questionnaire and Findings}

\subsection{Analyzing the questionnaire}

We used Microsoft Excel to analyze the questionnaire, owing to not having a large amount of data.

Question (1) is: (as a participant in the summer training course, to what extent are you satisfied with the time of participating the course?) three options have given to answer for this question (very satisfied, satisfied or unsatisfied). (65) Students out of (73) were unsatisfied with this course, while (6) of them were satisfied and only (2) students have mentioned that they were very satisfied of the course time. The main reason for asking this question is the majority of students are not happy with the time of summer training as it is noticed during the last 9 years, and the cause is students and even lecturers have only (2) months of holiday if they spent their holiday time with summer training so, they do not have any holiday time any more. As it is clear from figure (1). Question (2) is: (did the course make any issue for you? If yes please mention it). The answer of this question was (Yes or No). As it is clear from figure (2), (61) Out of (73) students have chosen (Yes) as the answer of this question. While, (No) have been chosen by (12) students. Some of the students have mentioned that they have second turn, so they will face problems for studying and, some of them have said they want to work during that holiday time. Spending holiday time in another country is another problem for some of the students as well.

Question (3) is: (as a participant, to what extent you were satisfied with the place of the course?) the answer was (satisfied, very satisfied, or unsatisfied). (54) Out of (73) students considered that the place was unsatisfied for them. (14) Of them were satisfied with the place and only (5) of the students were very satisfied. The reason is the governmental organization and private companies are limited thus, they may achieve a place for practicing summer training in far place of their houses as it is happening yearly for students who are come from outside the city especially at a last (2) years because of the financial crisis there is no replacing for supervisors. Therefore, they will not take any summer training because of the fees. Look at figure (3). 
Question (4) is: (if the collage makes a few agreements with private companies and you are doing your job in your department this will not be better for you, instead of going to another place?). The answer was (yes or no). clearly from figure (4) the majority of the students (63) out of (73) believe that working in their collage is better than going to another office without having any experience in that office. Hence, working with some people who are seen for the first time is not quite comfortable while, working in the collage with making groups is much better. Only (10) of them have said going to another place is better for practicing what they have learned during (3) years of studying in the University.

Question (5) is: (did you take any module throughout the four year of study, related to knowing how to deal with the administration department of another office or a company?) The answer was (Yes or No) unfortunately all of the students considered that they have not taken any modules to teach them how to deal with another party or company. While, when they are going to another company they have to have all abilities and skills in order to work and negotiate with them very carefully. Look at figure (5)

Question (6) is: (to what extent did your supervisor has knowledge or experience about the departments which you were dealing with during the course?) the answer was (more, likely more, none). From figure (6) it is clear that most of the students (46) mentioned that their supervisors have more knowledge about their departments. Whereas, likely more has chosen by (18) students and (9) of them believed that their supervisors have no knowledge.

Question (7) is: (to what extent does the department where you were attending had any relation with the area of your study?) the answer was (more, less, or none). (37) Of the students stated that the department has more relation with their specialist. While, (24) of them mentioned the department has none relation with their area of study and less relation has been chosen by (12) students. Look at figure (7)

Question (8) is: (during the training time, did you obtain enough knowledge in order to use it in your CV later?) the answer was (yes, to an extent, or no). (35) Of the students stated that they do not obtain enough knowledge to improve their $\mathrm{CV}$ in the future. However, (26) of them considered the course was to an extent useful for improving their CV. Hence, (12) of the responders believed that the course was good. The main reason for asking this question is sometimes especially in the governmental organizations they use some particular units for training which are really not close to the students' specialist. They do not want to make accounting units to be busy with the students. Finally, this will not be useful for students' knowledge. They practiced in the administration units. This is necessary for them but not as much as the accounting units. As it has demonstrated in figure (8)

Question (9) is: (does your participation in the summer training course lead to more job opportunity?) the answer was (Yes or No). (57) Out of (73) of the students considered that their participation does not make any job opportunity. However, only (16) of them mentioned that job opportunity has been achieved by their participation. This is clarifying by figure (9).

Question (10) is: (did the time interval was enough for you to learn the work of the governmental organization or private sectors?) the answer was (more likely, likely or unlikely). Some of them (13) mentioned the time was more likely to learn the work of their office and (24) of them considered time was likely for them to learn their job. However, time was unlikely for (36) students for learning their issue. Look at figure (10).

\section{- Findings:}

- time of the course:

As it is seen from the questionnaire the students are not satisfied with the time of the course. The reason is this time is allocated in front of the second term of examination which is July and August. On the other hand they have only 2 months of holiday to enjoy and participation in some hobby courses such as: English language, music, swimming and trips. Thus, it is better for students to complete their academic years consequently, otherwise they will not have any holidays. Another reason might be that these two months are very hot in this country some time the temperature will raise in to nearly 50 degree and the government should announce recess and this will make the course to be less benefit. Another reason might be that 2 months are not enough for students to learn and practice what they have studied.

- place of the course:

Clearly, the place of the course was not satisfied for students as well. The reason is place of the directorate might be far from student and supervisor's place of living. Consequently, they have to take risk to go there to complete their course. In a case of car crash no one will hold responsibility of their safety life even the government. For the students who are living outside the city they want to complete their course in their locality or clamp and there is no supervisor for them because after financial crisis there is no deputing. Therefore, the supervisors should hold all the costs by themselves while, the government is not spending their full monthly salary.

- job opportunity:

It is clear from the responders, that there is no job opportunity for them because, the majority of the students have participated the course in the governmental organizations and they do not appointing any one recently because of the financial crisis. On the other hand, if they are appointing peoples in the next 10 years there will be 
a large numbers of employees in the governmental organization and this will need a huge amount of budget just for paying monthly salaries without any other costs.

- Supervisors'specialist:

As it has clarified from the literature review, in the past duo to the lack of employees who have bachelor, MSc. or $\mathrm{PhD}$. The scientific unit has to decide put some employees to be a supervisor who have diploma degree and it is not logical for bachelors' student to have supervisor who has a degree which is under their degree. Fortunately, this problem has been solved owing to providing more $\mathrm{PhD}$ and MSc degree for the Universities.

\section{Conclusion}

This research can be concluded as that: the summer training is one of the most important parts for students' knowledge and it has to be completed by them but in a different way. It is very hard for students to go to another place for learning with no experience, no taking module to deal with companies and working for them in a way in which she/he can demonstrate her/his ability. On the other hand, it costs government a lot of budget to complete this part of bachelor degree in Kurdistan' Universities while, the government has faced financial crisis because of the decline of oil price. In addition, consultancy project can be revenue for government which means the government can make Universities to be a source of finance by earning money through these kinds of projects because depending on oil resources will bring difficulties in a case of decreasing oil prices which have been occurred in the last 2 years in Kurdistan. For these reasons consultancy project can be the best and only instruments to be used as an alternative for the summer training besides that, it helps students to manage much time and also save money because they do not need to go or attend a summer training course every day during the summer time.

\section{Suggestions}

The best suggestion here is this course should be taken during the normal academic year like any other modules and in their university without going to another governmental unit. This suggestion has been adopted in one of the past academic year but, it was not successful because this made the course books have not been completed, because, the students were going to their course twice a week and consequently the course book has been dely. One or two modules have to be studied in order to teach students how to deal with another company. The best suggestion is consultancy has to be taught with research method, a lecturer of research method should teach consultancy as well. The course book of research method should be updated in a way in which both of research and consultancy have to be taught in one module. One or two lecturer can teach this module by cooperating in which one of them teaches research method and the other one consultancy. Every year a committee should be formed to deal with the companies. They will give us their demands for doing some jobs for them depending on the students' specialist. The students will be forming by groups, each groups has their supervisor. The supervisor will be chosen according to specialist. Companies send their representative (client) as it is defined in literature review. The client will come to see students three times during their implementing projects. First time, at the beginning of the project, they will come to give the students their requirements, and then in the middle to see any enquiries from the students. Finally, after completing their jobs and writing a report about what they have done for them with a brief presentation. The students will take marks and the marks will offer by their supervisors not the client, because the supervisor knows who has tired and who has worked for the project. These companies have to pay money to the Universities. This money can be divided in to three parts as follows: for supervisors, finance directorate of University and Ministry of Finance.

\section{References}

BLOCK, Peter (2011). Flaw less consulting: a guide to getting your expertise used. 3th ed. San Francisco: Pfeiffer.

Caian, S. (2012). The evolution of the management consultancy market in Romania. Available at http://www.amcor.ro/noutati/Preedintele-AMCOR-dl- Sorin-Caian-Despre-evoluia-pieei-de-consultann-management-din Romnia. html.

Matei, I. (2013). Romania has become a country of consultants. One out of 20 firms gives advice to others]. Business Magazine (November 4, 2013). Available at http://www.businessmagazin.ro/coverstory/romania-a devenito-tara-de-consultanti-una-din-20-de-firme-da-sfaturi-altora 11615934.

Patrutescu, M. (2008) The role of financial and managerial consultancy in maintaining profitable business on the market, Review of Management and Economic Engineering, vol 7/ no. 4, pp. 129-134.

Vallini, C. (2007). Ethics in Management Consulting. Symphonya. Emerging Issues in Management.

VATAMANESCU, Elena-Madalina. (2014). Management Dynamics in the Knowledge Economy, vol. 2, Issue: 2286-2668, pp. 57-70.

\section{Appendix}


Table (1): showing students satisfaction with summer training.

\begin{tabular}{|c|c|}
\hline \multicolumn{2}{|c|}{ satisfying with summer training } \\
\hline \multicolumn{1}{|c|}{ Options } & $\underline{\text { No. of responses }}$ \\
\hline Very satisfied & 2 \\
\hline Satisfied & 6 \\
\hline Unsatisfied & 65 \\
\hline
\end{tabular}

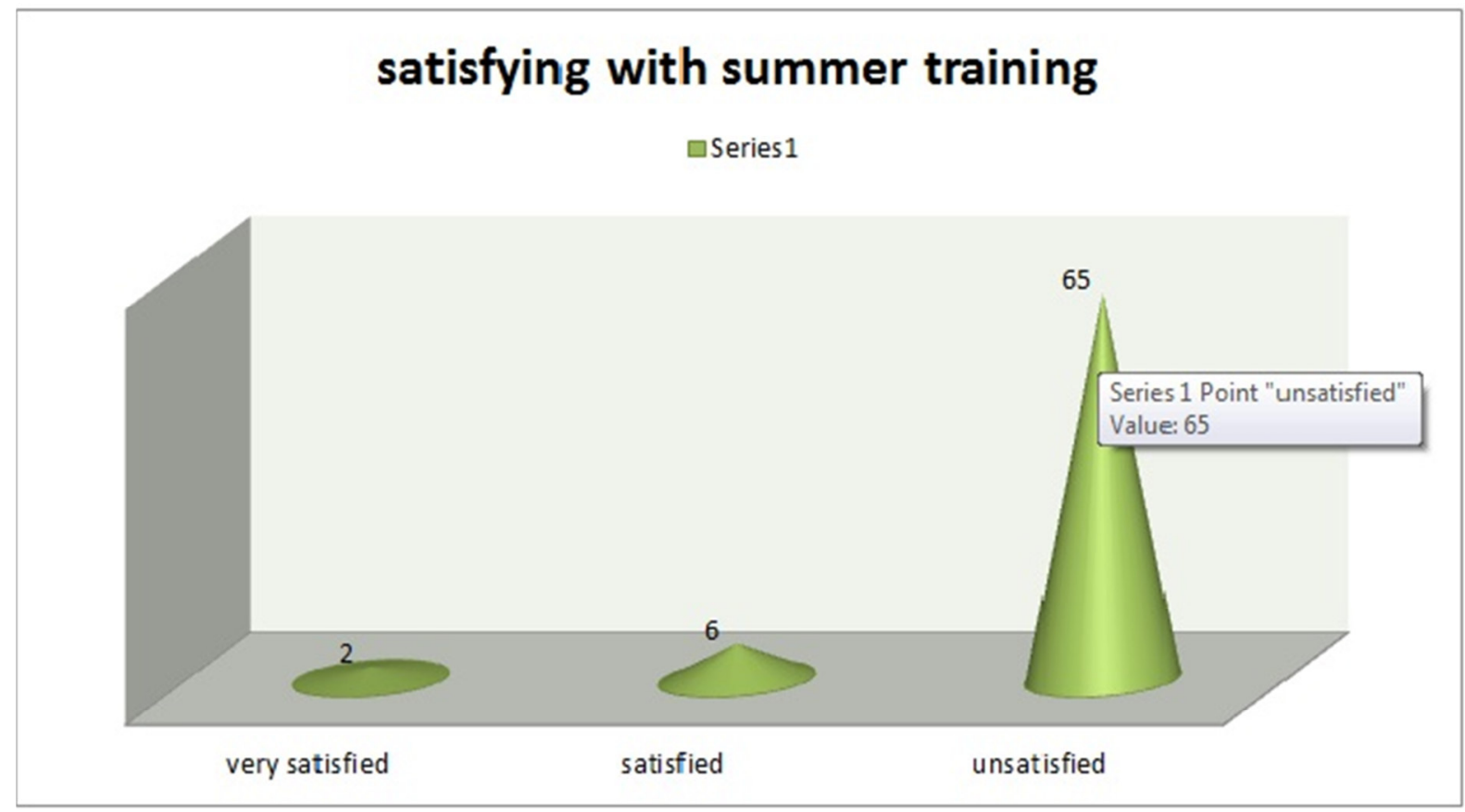

Figure (1): the trend of students' satisfaction with summer training.

Table (2): clarifying whether summer training has made a problem to students or not.

\begin{tabular}{|cc|}
\hline Options & making problems \\
\hline Yes & $\frac{\text { No. of responses }}{61}$ \\
\hline No & 12 \\
\hline
\end{tabular}




\section{making problems}

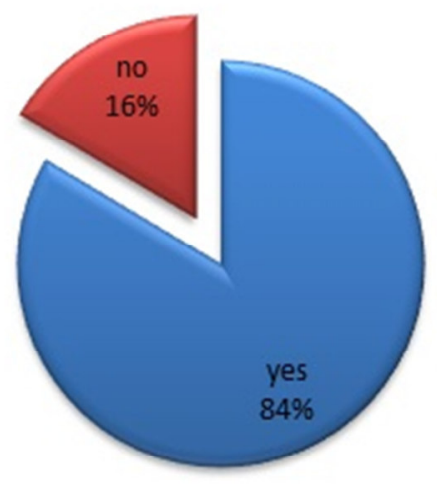

Figure (2): the trend of clarifying whether summer training has made a problem to students or not.

Table (3): illustrating students' satisfaction with the place of summer training.

\begin{tabular}{|c|c|}
\hline \multicolumn{1}{|c|}{ satisfying with the place of summer training } \\
\hline Satisfied & $\frac{\text { No. of responses }}{14}$ \\
\hline Very satisfied & 5 \\
\hline Unsatisfied & 54 \\
\hline
\end{tabular}

\section{satisfying with the place of summer training}

घatisfied $\square$ very satisfied $\square$ unsatisfied

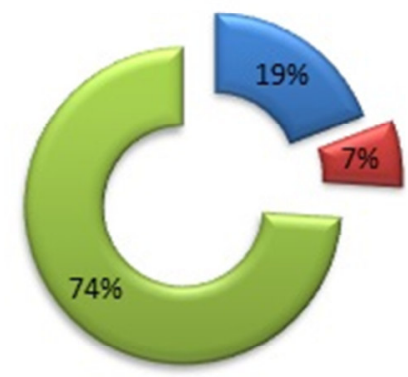

Figure (3): the trend of students' satisfaction with the place of summer training.

Table (4): demonstrating whether the students want to work as a consultant or not. working as a consultant

\begin{tabular}{|c|c|}
\hline Options & Norking as a consultant \\
\hline Yes & Nosponses \\
\hline no & 63 \\
\hline
\end{tabular}




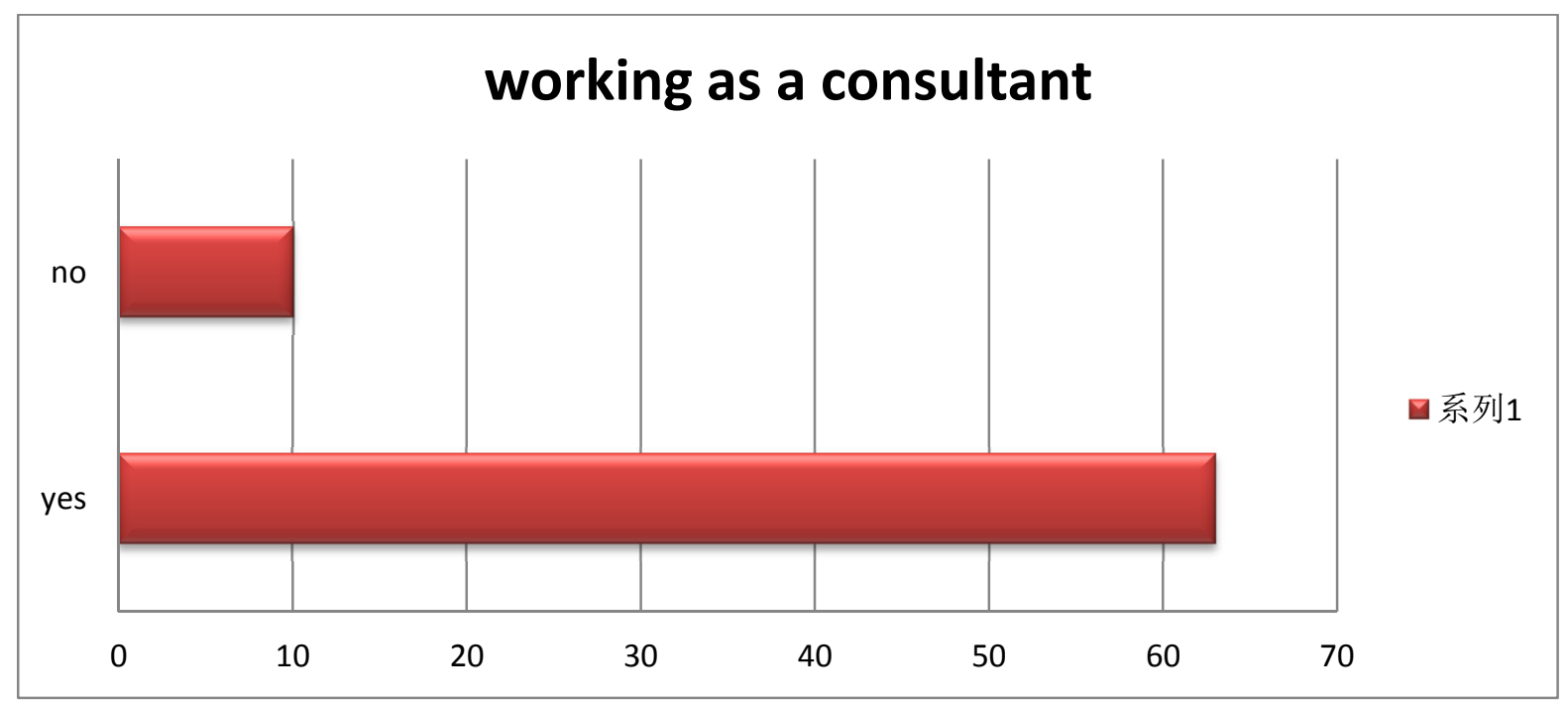

Figure (4): the trend of whether the students want to work as a consultant or not.

Table (5): showing whether students have consultancy as a module or not.

\begin{tabular}{|c|c|}
\hline \multicolumn{2}{|c|}{ having consultancy as a module } \\
\hline$\underline{\text { Options }}$ & $\frac{\text { No. of responses }}{2}$ \\
\hline Yes & 0 \\
\hline No & 73 \\
\hline
\end{tabular}

\section{having consultancy as a module}

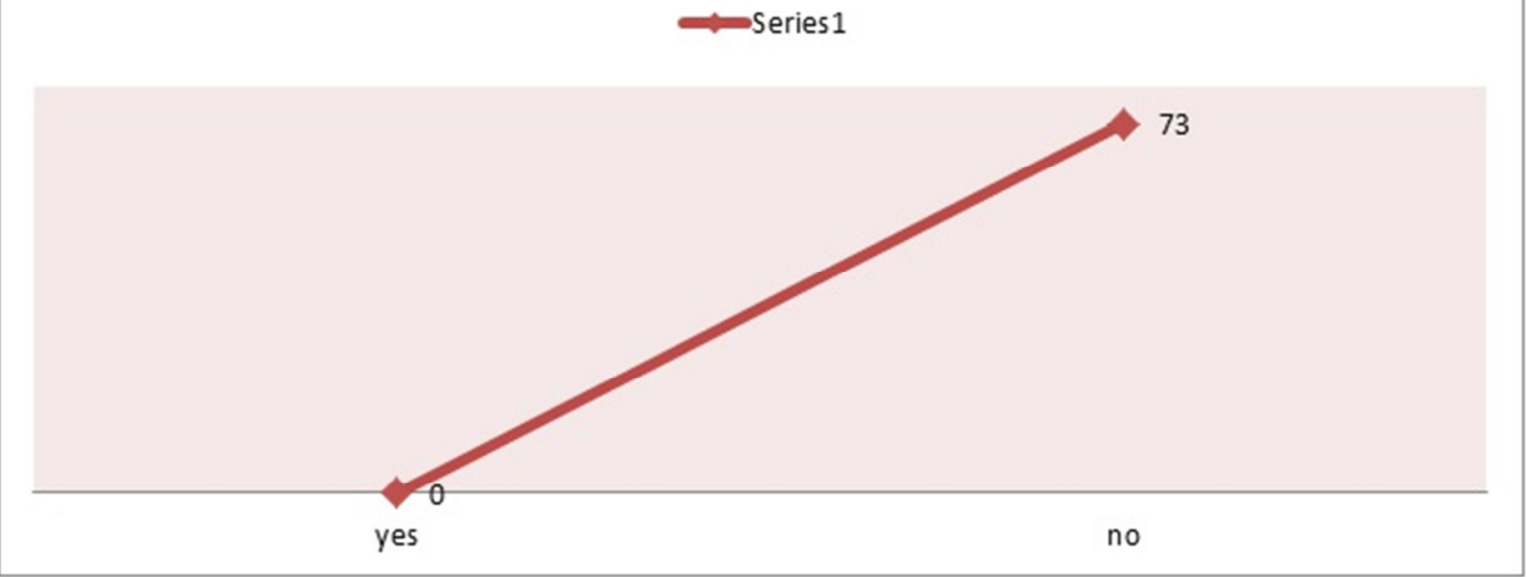

Figure (5): the trend whether students have consultancy as a module or not.

Table (6): clarifying the supervisors' knowledge.

\begin{tabular}{|c|c|}
\hline \multicolumn{2}{|c|}{ knowledge of the supervisor } \\
\hline Options & $\frac{\text { No. of responses }}{46}$ \\
\hline More & 18 \\
\hline Likely more & 9 \\
\hline None & 46 \\
\hline
\end{tabular}




\section{knowledge of the supervisor}

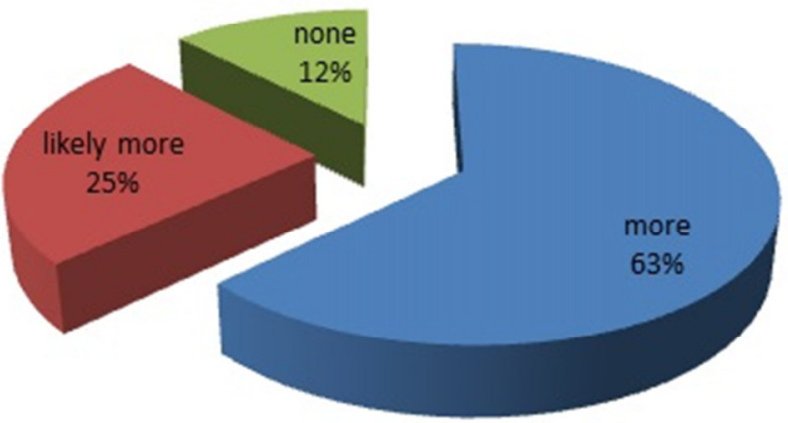

Figure (6): the trend of the supervisors' knowledge.

Table (7): relationship between the area of summer training and specialist.

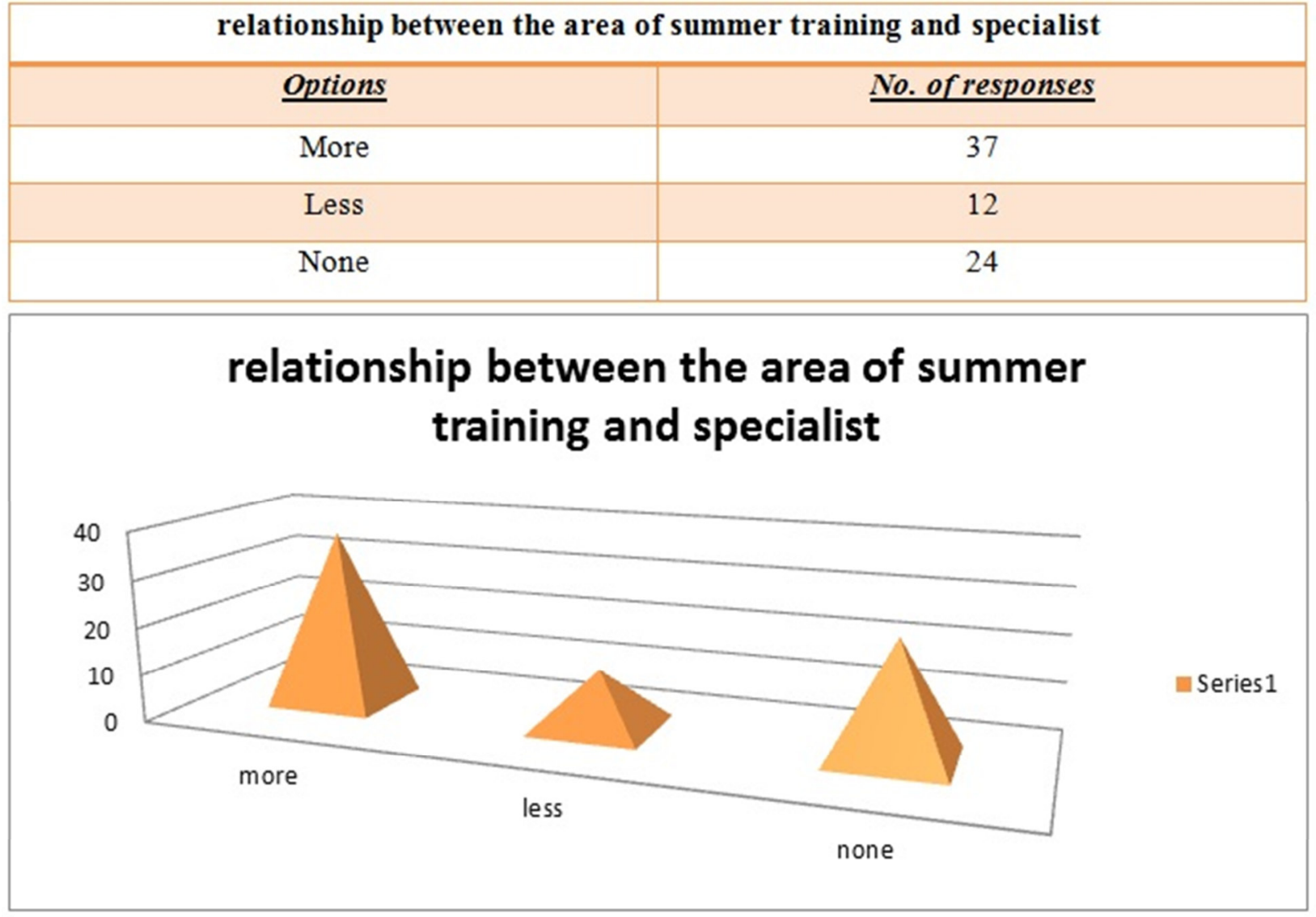

Figure (7): the trend of relationship between the area of summer training and specialist. 
Table (8): illustrating students' CV improvements due to summer training.

\begin{tabular}{|c|c|}
\hline \multicolumn{2}{|c|}{ CV Improvements } \\
\hline$\underline{\text { Options }}$ & $\frac{\text { No. of responses }}{12}$ \\
\hline Yes & 26 \\
\hline To an extent & 35 \\
\hline No & 12 \\
\hline
\end{tabular}

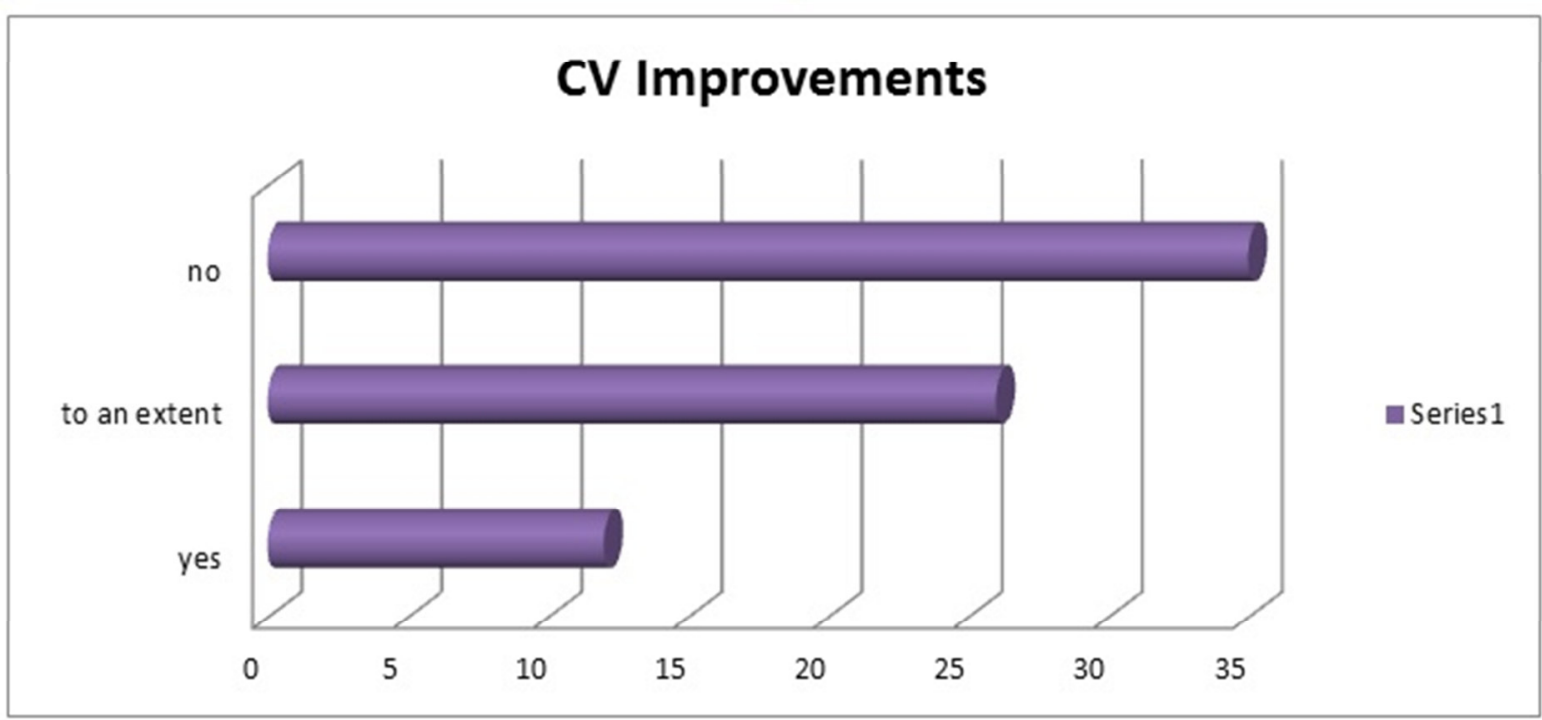

Figure (8): the trend of students' CV improvements due to summer training.

Table (9): demonstrating whether summer training gave the job opportunity to students or not.

\begin{tabular}{|c|c|}
\hline \multicolumn{2}{|c|}{ job opportunity } \\
\hline Options & $\frac{\text { No. of responses }}{16}$ \\
\hline Yes & 57 \\
\hline No & 57 \\
\hline
\end{tabular}

\section{job opportunity}

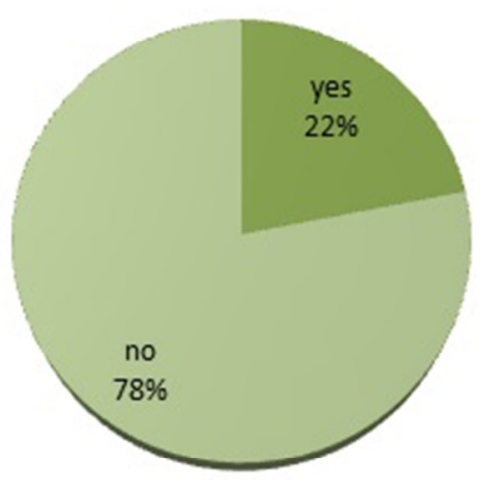

Figure (9): the trend of whether summer training gave the job opportunity to students or not. 
Table (10): showing that the time interval is enough to learn.

\begin{tabular}{|c|c|}
\hline \multicolumn{2}{|c|}{ time interval } \\
\hline Options & $\frac{\text { No. of responses }}{2}$ \\
\hline More likely & 13 \\
\hline Likely & 24 \\
\hline Unlikely & 36 \\
\hline
\end{tabular}

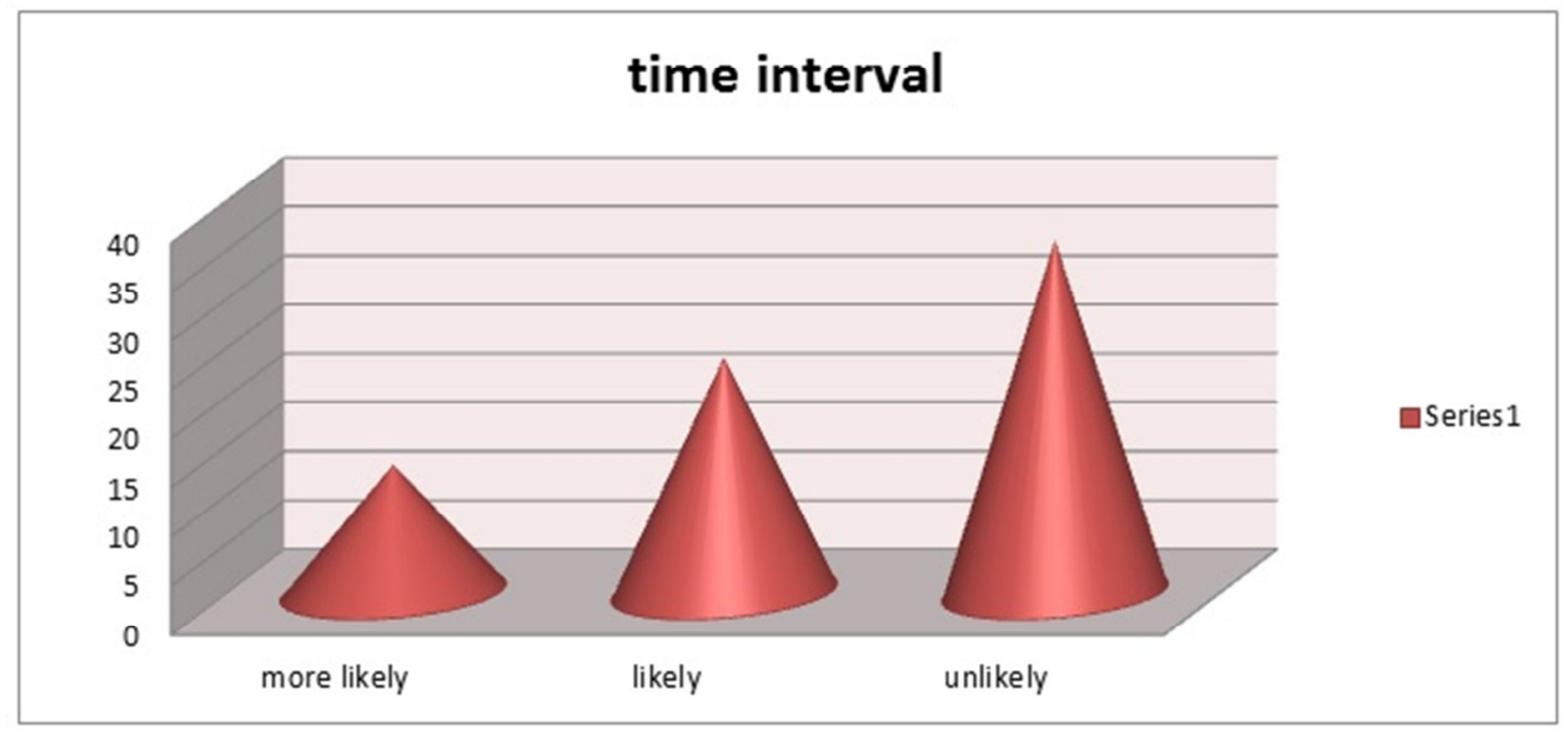

Figure (10): the trend of that the time interval is enough to learn. 